\title{
Beneficial effects of CPAP treatment on endothelial function in patients with mild to moderate obstructive sleep apnea
}

\author{
Seiko Miyata ${ }^{1}$, Akiko Noda ${ }^{2 *}$, Yoshinari Yasuda ${ }^{3}$, Mari Sugiura Kojima ${ }^{4}$, Sayuri Tsukano ${ }^{4}$, Tae Sugiura ${ }^{4}$, Yasuo Koike and Hironao Otake $^{1,6}$ \\ ${ }^{1}$ Department of Sleep Medicine, Nagoya University Graduate School of Medicine, Nagoya, Japan \\ ${ }^{2}$ Department of Biomedical Sciences, Chubu University Graduate School of Life and Health Sciences, Kasugai, Japan \\ ${ }^{3}$ Department of CKD Initiatives, Nagoya University Graduate School of Medicine, Nagoya, Japan \\ ${ }^{4}$ Department of Medical Technology, Nagoya University School of Health Sciences, Nagoya, Japan \\ ${ }^{5}$ Department of Clinical Engineering, Chubu University College of Life and Health Sciences, Kasugai, Japan \\ ${ }^{6}$ Department of Otorhinolaryngology, Nagoya University Graduate School of Medicine, Nagoya, Japan
}

\begin{abstract}
Purpose: Obstructive sleep apnea (OSA) is associated with endothelial dysfunction, which may contribute to the onset of atherosclerosis and associated complications. Flow-mediated dilation (FMD) is routinely used as a noninvasive technique to evaluate endothelial function. The aim of the study was to investigate the impact of continuous positive airway pressure (CPAP) treatment on endothelial function in OSA.

Methods: A cohort of twenty-five patients with OSA (age $53.8 \pm 11.8$ years) and 17 age-matched controls (age $48.1 \pm 15.1$ years) were included in the study. Systolic blood pressure (SBP) and diastolic blood pressure (DBP) were measured using a plethysmography. FMD was evaluated using high-resolution ultrasound with a 7.5 $\mathrm{MHz}$ linear array transducer. The \% FMD index was calculated as (maximum diameter - baseline diameter) / (baseline diameter) $\times 100$. Maximum carotid intimamedia thickness (max IMT) was also determined.

Results: \% FMD was significantly lower in OSA patients compared to controls ( $3.3 \pm 1.9$ vs. $5.0 \pm 1.9, P=0.009)$ while SBP, DBP, and max IMT did not significantly differ between the two groups. In OSA patients showing good CPAP adherence (defined as CPAP usage $\geq 4 \mathrm{~h} /$ night and $70 \%$ of nights), $\%$ FMD improved from 1.7 to 3.1 in the absence of any significant decrease in SBP or DBP.
\end{abstract}

Conclusion: Although there was no difference in max IMT between OSA patients and control subjects, \% FMD was significantly decreased in OSA patients. More particularly, our results suggest that good adherence to CPAP treatment might reverse endothelial dysfunction in these patients.

\section{Introduction}

Obstructive sleep apnea (OSA) is characterized by repetitive upper airway closure during sleep resulting in repeated reversible blood oxygen desaturation and fragmented sleep [1]. OSA has been increasingly linked with excess cardiovascular morbidity and mortality [2-4]. In previous studies, we showed that aortic pressure augmentation, an indicator of cardiovascular risk, was significantly increased in patients with OSA compared with healthy controls [5]. Our results were corroborated by reports showing that OSA directly affect vascular endothelial cells by inducing inflammation and oxidative stress [6]. Endothelial dysfunction was in turn found to precede or accelerate the development of atherosclerosis [7]. Nitric oxide metabolites was significantly reduced in OSA patients with an apnea/hypopnea index (AHI) $\geq 20 /$ h compared with those in healthy controls, which was correlated with OSA level of severity [8].

The first-line treatment for patients presenting OSA is continuous positive airway pressure (CPAP) therapy [9], which significantly ameliorates symptoms as well as its cardiovascular consequences [1012]. We previously showed that successful CPAP treatment improved daytime baroreflex sensitivity and nitric oxide production in patients with moderate to severe OSA, hence CPAP may reduce the risk of cardiovascular complications due to endothelial dysfunction or increased sympathetic activity [8]. Nevertheless, adherence to CPAP in daily clinical practice may often be problematic. When adherence is greater than 4 hours of nightly use, 46 to $83 \%$ of OSA patients were reported to be nonadherent to the treatment [13]. Increasing daily use of CPAP lowers blood pressure [10] and reduces the risk of incident stroke [11] and cardiovascular death [12]. Vascular endothelial dysfunction and structural vascular changes have been implicated as early mechanisms in the pathophysiology of hypertension and other forms of vascular disease [14]. Using non-invasive imaging techniques for the determination of flow-mediated dilation (FMD) and carotid intima-media thickness (IMT) - which are commonly used as surrogate markers of atherosclerosis - may help with risk stratification [15-17].

Correspondence to: Akiko Noda, $\mathrm{PhD}$, Department of Biomedical Sciences, Chubu University, Graduate School of Life and Health Sciences, 1200 Matsumoto-cho, Kasugai-shi, Aichi, 487-8501, Japan, E-mail: anoda@isc.chubu.ac.jp

Key words: obstructive sleep apnea, atherosclerosis, flow-mediated dilation, continuous positive airway pressure, carotid intima-media thickness

Received: April 10, 2017; Accepted: May 16, 2017; Published: May 19, 2017 
The aim of this study was to investigate the impact of mild to moderate on FMD as well as the changes associated with CPAP treatment in OSA patients.

\section{Methods}

\section{Patients}

A cohort of 25 patients clinically diagnosed with OSA (age 53.8 \pm 11.8 years) and 17 age-matched healthy male controls (age $48.1 \pm$ 15.1 years), as determined using out-of-center sleep test. Eight of the 25 patients (age $49.9 \pm 4.1$ years) were eligible for CPAP treatment and underwent therapy for more than four weeks ( $4.0 \pm 2.7$ months). The same patients were studied before and after CPAP therapy. CPAP usage was evaluated as the total number of hours of CPAP mask on divided by the total number of study days, which was downloaded with software. Good CPAP adherence was defined as the good CPAP users who used CPAP for $\geq 4 \mathrm{~h} /$ night for at least $70 \%$ of study nights [18]. This study was approved by the Ethics Review Committee of Nagoya University School of Medicine.

\section{Polysomnography (PSG)}

All patients diagnosed with OSA underwent standard polysomnography (Alice 3; Respironics, Murrysville, USA). The polysomnography consisted of continuous polygraphic recordings of electroencephalography $\left(\mathrm{F}_{3}-\mathrm{A}_{2}, \mathrm{~F}_{4}-\mathrm{A}_{1}, \mathrm{C}_{3}-\mathrm{A}_{2}, \mathrm{C}_{4}-\mathrm{A}_{1}, \mathrm{O}_{1}-\mathrm{A}_{2}, \mathrm{O}_{2}-\right.$ $\mathrm{A}_{1}$ ), electrooculography, electromyography, electrocardiography, oronasal airflow with an oronasal thermistor and a pressure sensor, and thoracoabdominal motion with piezo sensors. Oxygen saturation $\left(\mathrm{SpO}_{2}\right)$ was monitored by a pulse oximeter. Apnea was defined as a cessation of airflow through the mouth and nose lasting for $\geq 10$ seconds, and a hypopnea was defined as a $\geq 50 \%$ reduction in airflow accompanied by either oxygen desaturation $\geq 3 \%$ or an arousal lasting for $\geq 10$ seconds. AHI was determined as the number of apnea and hypopnea episodes per hour, and OSA was diagnosed when AHI was $\geq 5$ episodes / hour and Epworth sleepiness score $\geq 11$. The $3 \%$ oxygen desaturation per hour (oxygen desaturation index: ODI), lowest $\mathrm{SpO}_{2}$ and arousal index were evaluated in line with the guidelines of the American Academy of Sleep Medicine Manual for the Scoring of Sleep and Associated Events [19].

\section{Brachial artery FMD}

We followed the expert guideline to determine FMD defined by the percentage increase in the diastolic diameter of the brachial artery before and after forearm cuff inflation to induce ischemia in the ipsilateral hand (reactive hyperemia) [20]. A continuous three-lead ECG was recorded and used to identify the time to onset of diastole. A blood pressure cuff was placed on the right distal forearm. The right brachial artery images were obtained above the antecubital fossa using B-mode imaging in the longitudinal plane of the artery using a 7.5 $\mathrm{MHz}$ linear transducer (Prosounda10, Hitachi-Aloka Medical, Mitaka, Japan). FMD was induced by inflating the forearm cuff to $50 \mathrm{~mm} \mathrm{Hg}$ over systolic blood pressure (SBP) at rest. Rest blood pressure was measured using a plethysmography after 5 minutes of bed rest. The diameter of the brachial artery was assessed for 60 to $90 \mathrm{~s}$ after deflation of the cuff. \% FMD was computed with (maximum diameter-baseline diameter) / baseline diameter $\times 100$.

\section{Carotid IMT}

Carotid artery IMT was assessed by B-mode ultrasound scanning with a 7.5-MHz linear phase array transducer (Prosounda10, Hitachi-
Aloka Medical, Mitaka, Japan). Both the left and right common carotid arteries were imaged at the level of the carotid bifurcation, using longitudinal B-mode ultrasonography. Maximum IMT (max IMT) was defined as the single thickest wall among near and far wall on both sides of the common carotid arteries, carotid sinus, and internal carotid artery [21].

\section{Statistical analysis}

Data were represented as mean \pm standard deviation (SD). Normal distribution was assessed using Shapiro-Wilk test. Non-paired Student's t-test was applied to body mass index (BMI), SBP, diastolic blood pressure (DBP), and \%FMD. Mann-Whitney's U test was used for max IMT to compare the differences between OSA patients and controls. The correlation between the various indices was investigated by Pearson and Spearman correlation analysis, and in OSA patients, the relationships between \%FMD and $\mathrm{AHI}$, ODI, lowest $\mathrm{SpO}_{2}$, and arousal index were evaluated using Pearson correlation analysis. Wilcoxon signed-rank test was used for comparison of \%FMD, SBP, and DBP before and after CPAP therapy. All statistical tests were twosided, and a $P$-value $<0.05$ was considered statistically significant. Data were analyzed with SPSS statistic package version 22.0 (IBM, Armonk, New York, USA).

\section{Results}

The \%FMD was significantly lower in OSA patients compared to control subjects $(3.3 \pm 1.9$ vs. $5.0 \pm 1.9, P=0.009)$. On the other hand, max IMT was not significantly different between the two groups. Similarly, no significant difference was found in relation to BMI, SBP, and DBP (Table 1). There were no significant correlation between $\%$ FMD and age, BMI, SBP, DBP, or max IMT. In patients presenting OSA, \%FMD did not show any significant correlations with AHI, ODI, lowest $\mathrm{SpO}_{2}$, and arousal index.

In all the patients who underwent CPAP therapy, FMD, SBP, and DBP did not significantly differ. However, in the four patients who showed good CPAP adherence, \%FMD tended to increase from 1.7 (range: 0.5-3.6) to 3.1 (range: $0.8-5.0, P=0.068$ ) in the absence of a decrease in SBP or DBP. In the four patients who admitted poor CPAP adherence, \%FMD after CPAP therapy tended to be worse from 5.2 (range: 4.1-7.5) to 3.2 (range: $0.2-6.8, P=0.068$ ) (Table 2).

\section{Discussion}

In the present study, we showed that \%FMD was lower in OSA patients compared to control subjects, while SBP, DBP and max IMT failed to show any significant differences between the two groups. In patients showing good CPAP adherence, improved \%FMD values were observed. These results suggest that good CPAP adherence may be

Table 1. Comparison of characteristics between OSA patients and control subjects

\begin{tabular}{|c|c|c|c|}
\hline & OSA patients & Control subjects & P value \\
\hline $\mathrm{n}$ & 25 & 17 & - \\
\hline Age, yrs & $53.8 \pm 11.8$ & $48.1 \pm 15.1$ & 0.184 \\
\hline Male, $\mathrm{n}(\%)$ & $24(96.0)$ & $13(76.4)$ & 0.077 \\
\hline BMI, $\mathrm{kg} / \mathrm{m}^{2}$ & $29.0 \pm 4.7$ & $25.1 \pm 7.5$ & 0.052 \\
\hline SBP, $\mathrm{mmHg}$ & $133.5 \pm 15.5$ & $135.0 \pm 16.1$ & 0.779 \\
\hline DBP, $\mathrm{mmHg}$ & $83.2 \pm 12.3$ & $82.8 \pm 14.4$ & 0.931 \\
\hline \%FMD & $3.3 \pm 1.9$ & $5.0 \pm 1.9$ & 0.009 \\
\hline Max IMT, mm & $1.2 \pm 0.4$ & $1.1 \pm 0.5$ & 0.126 \\
\hline
\end{tabular}

BMI: body mass index; DBP: diastolic blood pressure; FMD: flow mediated dilation; IMT: intima-media thickness; OSA: obstructive sleep apnea; SBP: systolic blood pressure. 
Table 2. Comparison between \%FMD before and on CPAP therapy

\begin{tabular}{|c|c|c|c|c|c|c|c|}
\hline & \multirow{2}{*}{$\begin{array}{l}\text { AHI before } \\
\text { CPAP, /h }\end{array}$} & \multicolumn{2}{|c|}{$\mathrm{SBP}, \mathrm{mmHg}$} & \multicolumn{2}{|c|}{ DBP, $\mathrm{mmHg}$} & \multicolumn{2}{|c|}{$\%$ FMD } \\
\hline & & Before CPAP & On CPAP & Before CPAP & On CPAP & Before CPAP & On CPAP \\
\hline \multicolumn{8}{|c|}{ Total CPAP users } \\
\hline & $55.0 \pm 23.4$ & $131.0 \pm 15.4$ & $135.3 \pm 14.0$ & $83.6 \pm 8.4$ & $88.8 \pm 7.7$ & $3.4 \pm 2.3$ & $3.1 \pm 2.3$ \\
\hline & & \multicolumn{2}{|c|}{$P=0.233$} & \multicolumn{2}{|c|}{$P=0.079$} & \multicolumn{2}{|c|}{$P=1.000$} \\
\hline \multicolumn{8}{|c|}{ Good CPAP users } \\
\hline Case 1 & 69.2 & 162 & 158 & 92 & 87 & 1.3 & 2.1 \\
\hline Case 2 & 33.7 & 120 & 132 & 73 & 89 & 3.6 & 5.0 \\
\hline Case 3 & 77.3 & 122 & 121 & 78 & 77 & 1.3 & 4.5 \\
\hline Case 4 & 64.7 & 130 & 147 & 86 & 89 & 0.5 & 0.8 \\
\hline \multirow{2}{*}{ Mean \pm SD } & \multirow{2}{*}{$61.2 \pm 19.1$} & $133.5 \pm 19.5$ & $139.5 \pm 16.3$ & $82.3 \pm 8.4$ & $85.5 \pm 5.7$ & $1.7 \pm 1.3$ & $3.1 \pm 2.0$ \\
\hline & & \multicolumn{2}{|c|}{$P=0.465$} & \multicolumn{2}{|c|}{$P=0.715$} & \multicolumn{2}{|c|}{$P=0.068$} \\
\hline \multicolumn{8}{|c|}{ Poor CPAP users } \\
\hline Case 5 & 56.3 & 117 & 123 & 82 & 85 & 4.8 & 0.2 \\
\hline Case 6 & 85.8 & 133 & 121 & 80 & 93 & 7.5 & 6.8 \\
\hline Case 7 & 25.9 & 144 & 147 & 99 & 104 & 4.1 & 3.9 \\
\hline Case 8 & 26.8 & 120 & 133 & 79 & 86 & 4.4 & 1.7 \\
\hline \multirow{2}{*}{ Mean \pm SD } & \multirow{2}{*}{$48.7 \pm 28.5$} & $128.5 \pm 12.4$ & $131.0 \pm 11.9$ & $85.0 \pm 9.4$ & $92.0 \pm 8.8$ & $5.2 \pm 1.6$ & $3.2 \pm 2.9$ \\
\hline & & \multicolumn{2}{|c|}{$P=0.465$} & \multicolumn{2}{|c|}{$P=0.068$} & \multicolumn{2}{|c|}{$P=0.068$} \\
\hline
\end{tabular}

AHI: apnea/hypopnea index; CPAP: continuous positive airway pressure; DBP: diastolic blood pressure; FMD: flow mediated dilation; SBP: systolic blood pressure.

help address endothelial dysfunction, a commonly observed feature of patients presenting OSA.

Repeated hypoxia during sleep in patients with OSA may induce systemic inflammation and oxidative stress $[22,23]$ and as a result, contribute to the development of endothelial dysfunction [17]. Endothelial dysfunction promotes the development and clinical manifestation of atherosclerosis. FMD has been routinely used as a noninvasive approach to evaluate endothelial function. Previous authors reported that, in patients with OSA, the decrease in FMD correlated with the degree of endothelial cell apoptosis and, CPAP therapy led to a significant decline in levels of circulating apoptotic endothelial cells [24]. In our study, patients with OSA showed a significant decrease in \%FMD compared to control subjects. On the other hand, max IMT values were determined not to be significantly different between the two groups. We thus demonstrated that endothelial function was impaired in patients with OSA.

CPAP therapy has a variety of beneficial effects on the cardiovascular system, such as decrease in blood pressure and nitric oxide [25]. A six month-course CPAP therapy significantly increased \%FMD in normotensive OSA patients who had a good CPAP adherence while the levels failed to change in non-CPAP users, who did not tolerate using the device [26]. Our study also demonstrated that \%FMD was increased in patients with good CPAP adherence, meanwhile, it was decreased in patients with poor CPAP adherence. Previous studies showed that the 5-year cumulative survival rate improved as CPAP adherence increased, and the association between CPAP adherence and mortality was independent of other covariates including age and hypertension amongst the 871 patients diagnosed with OSA [27]. The same authors suggested that the undue stress on cardiovascular system would disappear in patients with OSA if they underwent adequate CPAP therapy i.e., $\geq 4 \mathrm{~h} /$ night and $70 \%$ of nights.

Higher carotid IMT has been associated with higher risk of cardiovascular disease [28]. There was no significant difference in IMT between OSA patients and controls, and IMT did not show significant correlation to \%FMD in this study. Recent study reported that carotid IMT in patients with OSA was significantly higher than those in obese controls [29]. IMT was significantly higher in patients with severe
OSA compared to patients with mild to moderate OSA or controls. Interestingly, no significant difference was determined between control subjects and patients with mild to moderate OSA [30]. In middle-aged healthy men, there was no significant correlation between carotid IMT and brachial artery FMD, suggesting that these two markers may be associated with different stages of atherogenesis [31]. Further investigations are required to confirm the association between OSA and IMT as risk factors for cardiovascular disease.

In conclusion, \%FMD was determined to be significantly lower in OSA patients, although no significant differences were found in SBP, DBP and max IMT between OSA patients and control subjects. \%FMD was improved when patients adhere to a CPAP treatment course of at least 4 weeks. Our findings suggest that endothelial function was impaired in patients presenting OSA and that this impairment may be reversed upon adequate CPAP treatment.

\section{Acknowledgement}

This study was partly supported by JSPS Kakenhi Grant Number $16 \mathrm{~K} 16600$.

\section{Conflict of interest}

\section{No}

\section{References}

1. Phillips B (2005) Sleep-disordered breathing and cardiovascular disease. Sleep Med Rev 9: 131-140. [Crossref]

2. Marshall NS, Wong KK, Liu PY, Cullen SR, Knuiman MW, et al. (2008) Sleep apnea as an independent risk factor for all-cause mortality: the Busselton Health Study. Sleep 31: 1079-1085. [Crossref]

3. Marin JM, Carrizo SJ, Vicente E, Agusti AG (2005) Long-term cardiovascular outcomes in men with obstructive sleep apnoea-hypopnoea with or without treatment with continuous positive airway pressure: an observational study. Lancet 365: 10461053. [Crossref]

4. Noda A, Okada T, Yasuma F, Sobue T, Nakashima N, et al. (1998) Prognosis of the middle-aged and aged patients with obstructive sleep apnea syndrome. Psychiatry Clin Neurosci 52: 79-85. [Crossref]

5. Noda A, Nakata S, Fukatsu H, Yasuda Y, Miyao E, et al. (2008) Aortic pressure augmentation as a marker of cardiovascular risk in obstructive sleep apnea syndrome. Hypertens Res 31: 1109-1114. [Crossref] 
6. Jelic S, Padeletti M, Kawut SM, Higgins C, Canfield SM, et al. (2008) Inflammation, oxidative stress, and repair capacity of the vascular endothelium in obstructive sleep apnea. Circulation 118: 2270-2278. [Crossref]

7. Ross R (1999) Atherosclerosis--an inflammatory disease. N Engl J Med 340: 115-126. [Crossref]

8. Noda A, Nakata S, Koike Y, Miyata S, Kitaichi K, et al. (2007) Continuous positive airway pressure improves daytime baroreflex sensitivity and nitric oxide production in patients with moderate to severe obstructive sleep apnea syndrome. Hypertens Res 30: 669-676. [Crossref]

9. Basner RC (2007) Continuous positive airway pressure for obstructive sleep apnea. $N$ Engl J Med 356: 1751-1758. [Crossref]

10. Yang MC, Huang YC, Lan CC, Wu YK, Huang KF (2015) Beneficial effects of longterm CPAP treatment on sleep quality and blood pressure in adherent subjects with obstructive sleep apnea. Respir Care 60: 1810-1818. [Crossref]

11. Campos-Rodriguez F, Martinez-Garcia MA, Reyes-Nuñez N, Caballero-Martinez I, Catalan-Serra P, et al. (2014) Role of sleep apnea and continuous positive airway pressure therapy in the incidence of stroke or coronary heart disease in women. $\mathrm{Am} \mathrm{J}$ Respir Crit Care Med 189: 1544-1550. [Crossref]

12. Martínez-García MA, Campos-Rodríguez F, Catalán-Serra $P$, Soler-Cataluña JJ, Almeida-Gonzalez C, et al. (2012) Cardiovascular mortality in obstructive sleep apnea in the elderly: role of long-term continuous positive airway pressure treatment: a prospective observational study. Am J Respir Crit Care Med 186: 909-916. [Crossref]

13. Weaver TE, Grunstein RR (2008) Adherence to continuous positive airway pressure therapy: the challenge to effective treatment. Proc Am Thorac Soc 5: 173-178. [Crossref]

14. Furchgott RF (1983) Role of endothelium in responses of vascular smooth muscle. Circ Res 53: 557-573. [Crossref]

15. Yeboah J, Crouse JR, Hsu FC, Burke GL, Herrington DM (2007) Brachial flowmediated dilation predicts incident cardiovascular events in older adults: the Cardiovascular Health Study. Circulation 115: 2390-2397. [Crossref]

16. Juonala M, Viikari JS, Laitinen T, Marniemi J, Helenius H, et al. (2004) Interrelations between brachial endothelial function and carotid intima-media thickness in young adults: the cardiovascular risk in young Finns study. Circulation 110: 2918-2923. [Crossref]

17. Lorenz MW, Markus HS, Bots ML, Rosvall M, Sitzer M (2007) Prediction of clinical cardiovascular events with carotid intima-media thickness: a systematic review and meta-analysis. Circulation 115: 459-467. [Crossref]

18. Lai AY, Fong DY, Lam JC, Weaver TE, Ip MS (2014) The efficacy of a brief motivational enhancement education program on CPAP adherence in OSA: a randomized controlled trial. Chest 146: 600-610. [Crossref]
19. Iber C, Ancoli-Israel S, Chesson A, Quan SF (2007) The AASM manual for the scoring of sleep and associated events: rules, terminology, and technical specification. 1st ed. Westchester, IL: American Academy of Sleep Medicine.

20. Thijssen DH, Black MA, Pyke KE, Padilla J, Atkinson G, et al. (2011) Assessment of flow-mediated dilation in humans: a methodological and physiological guideline. Am J Physiol Heart Circ Physiol 300: H2-12. [Crossref]

21. Joint committee with the guidelines subcommittee of the Japan Academy of Neurosonology for ultrasonic assessment of carotid artery disease and the subcommittee for research into methods of screening atherosclerotic lesions. (2002) Guidelines for ultrasonic assessment of carotid artery disease: preliminary report. Neurosonology 15: 20-33.

22. Minoguchi K, Yokoe T, Tazaki T, Minoguchi H, Oda N, et al. (2007) Silent brain infarction and platelet activation in obstructive sleep apnea. Am J Respir Crit Care Med 175: 612-617. [Crossref]

23. Schulz R, Mahmoudi S, Hattar K, Sibelius U, Olschewski H, et al. (2000) Enhanced release of superoxide from polymorphonuclear neutrophils in obstructive sleep apnea: impact of continuous positive airway pressure therapy. Am J Respir Crit Care Med 162: 566-570. [Crossref]

24. El Solh AA, Akinnusi ME, Baddoura FH, Mankowski CR (2007) Endothelial cel apoptosis in obstructive sleep apnea: a link to endothelial dysfunction. Am J Respir Crit Care Med 175: 1186-1191. [Crossref]

25. Caples SM, Garcia-Touchard A, Somers VK (2007) Sleep-disordered breathing and cardiovascular risk. Sleep 30: 291-303. [Crossref]

26. Bayram NA, Ciftci B, Keles T, Durmaz T, Turhan S, et al. Endothelial function in normotensive men with obstructive sleep apnea before and 6 months after CPAP treatment. Sleep 32: 1257-1263. [Crossref]

27. Campos-Rodriguez F, Peña-Griñan N, Reyes-Nuñez N, De la Cruz-Moron I, PerezRonchel J, et al. (2005) Mortality in obstructive sleep apnea-hypopnea patients treated with positive airway pressure. Chest 128: 624-633. [Crossref]

28. Vlachopoulos C, Xaplanteris P, Aboyans V, Brodmann M, Cífková R, et al. (2015) The role of vascular biomarkers for primary and secondary prevention. A position pape from the European Society of Cardiology Working Group on peripheral circulation: Endorsed by the Association for Research into Arterial Structure and Physiology (ARTERY) Society. Atherosclerosis 241: 507-532. [Crossref]

29. Minoguchi K, Yokoe T, Tazaki T, Minoguchi H, Tanaka A, et al. (2005) Increased carotid intima-media thickness and serum inflammatory markers in obstructive sleep apnea. Am J Respir Crit Care Med 172: 625-630. [Crossref]

30. Drager LF, Bortolotto LA, Lorenzi MC, Figueiredo AC, Krieger EM, et al. (2005) Early signs of atherosclerosis in obstructive sleep apnea. Am J Respir Crit Care Med 172 613-618. [Crossref]

31. Yan RT, Anderson TJ, Charbonneau F, Title L, Verma S, et al. (2005) Relationship between carotid artery intima-media thickness and brachial artery flow-mediated dilation in middle-aged healthy men. J Am Coll Cardiol 45: 1980-1986. [Crossref]

Copyright: (C2017 Miyata S. This is an open-access article distributed under the terms of the Creative Commons Attribution License, which permits unrestricted use, distribution, and reproduction in any medium, provided the original author and source are credited. 